\title{
ITRAQ-Based Proteomics Analysis of Acute Lung Injury Induced by Oleic Acid in Mice
}

\author{
Xiaotao Xu $\mathrm{Xu}^{\mathrm{a}}$ Qingwei Zhu ${ }^{\mathrm{b}}$ Rong Zhang ${ }^{\mathrm{a}}$ Yan Wang ${ }^{\mathrm{a}}$ Fangfang Niu ${ }^{\mathrm{a}}$ \\ Wenying Wang $^{\mathrm{a}}$ Dawei Sun ${ }^{\mathrm{a}}$ Aizhong Wang ${ }^{\mathrm{a}}$ \\ aDepartment of Anesthesiology, Shanghai Jiao Tong University Affiliated Sixth People's Hospital, \\ Shanghai, b'Department of Neurosurgery, Shanghai Jiao Tong University Affiliated Sixth People's \\ Hospital, Shanghai, China
}

\section{Key Words}

Lung injury • Oleic acid • Proteomics $•$ ITRAQ $・$ Antithrombin III

\begin{abstract}
Background/Aims: This study was conducted to investigate the relationship between differentially expressed proteins (DEPs) and the pathogenesis of oleic acid (OA)-induced acute lung injury (ALI) in mice. Methods: Eight-week-old male C57BL/6 mice were injected with $O A$ through the tail vein and sacrificed 6 hours after OA administration to identify protein expression levels in lung tissue using isobaric tags for relative and absolute quantification (iTRAQ) technology. Then, DEPs such as antithrombin III (AT III), 12-lipoxygenase (12-LO), dedicator of cytokinesis 2 (DOCK2), polycystin-2 and plasminogen were identified by western blotting. Subsequently, we focused on investigating the effect of AT III on endothelial integrity using siRNA interference technology. The levels of IL-6, IL-1 $\beta$, TNF- $\alpha$ and TGF- $\beta$ expression were detected using an enzyme-linked immunosorbent assay (ELISA). Alterations in the tight junction component ZO-1 and the phosphorylation of myosin light chain (pMLC) were determined by western blotting. The stress fiber $\mathrm{F}$-actin were also detected by immunofluorescence staining. In addition, endothelial permeability was determined via a transwell permeability assay. Results: A total of 5152 proteins were found to be expressed in lung tissues from the OA-treated and saline-treated mice. Among these proteins, 849 were differentially expressed between the two groups, including 545 upregulated and 304 downregulated proteins. After AT III knockdown, the levels of inflammatory factors and endothelial permeability were elevated, the expression of ZO-1 was decreased, and the expression of F-actin and PMLC was increased. All these results illustrated that AT III knockdown exaggerated the disruption of endothelial integrity mediated by OA. Conclusion: These findings using ITRAQ technology demonstrate, for the first time, differences in the lung tissue expression levels of proteins between OA-treated mice and saline-treated mice. This study reveals that $12-$ LO, DOCK2 and especially AT III may be candidate biomarkers for OA-induced acute lung injury.
\end{abstract}




\section{Introduction}

In 2001, the acute respiratory distress syndrome (ARDS) was redefined by experts convened in Berlin. The Berlin definition of ARDS included three categories based on degree of hypoxemia: mild ( $\left.200 \mathrm{~mm} \mathrm{Hg}<\mathrm{PaO}_{2} / \mathrm{FiO}_{2} \leq 300 \mathrm{~mm} \mathrm{Hg}\right)$, moderate $(100 \mathrm{~mm} \mathrm{Hg}<$ $\left.\mathrm{PaO}_{2} / \mathrm{FiO}_{2} \leq 200 \mathrm{~mm} \mathrm{Hg}\right)$, and severe $\left(\mathrm{PaO}_{2} / \mathrm{FiO}_{2} \leq 100 \mathrm{~mm} \mathrm{Hg}\right)$. In addition, four ancillary variables were also used to assess the severe ARDS: radiographic severity, respiratory system compliance $\left(\leq 40 \mathrm{~mL} / \mathrm{cm} \mathrm{H}_{2} \mathrm{O}\right)$, positive end-expiratory pressure $\left(\geq 10 \mathrm{~cm} \mathrm{H}_{2} \mathrm{O}\right)$, and corrected expired volume per minute ( $\geq 10 \mathrm{~L} / \mathrm{min}$ ) [1, 2]. ARDS is characterized by massive inflammatory cell infiltration, increased capillary permeability, severe alveolar damage and the formation of hyaline membranes [3-6]. The primary insults leading to ARDS include microbial infection, pollutants, toxic gasses, gastric acids, autoantibodies, fatty emboli, free fatty acids and transfusion [7, 8].

Within the past several years, isobaric tags for relative and absolute quantification (iTRAQ) technology has been used to investigate idiopathic pulmonary fibrosis [9] and hepatic ischemia-reperfusion-induced lung injury [10]. However, to our knowledge, no previous studies have used quantitative proteomics technologies to identify DEPs and their associated signaling pathways in OA-induced ALI.

To detect the potential biomarkers that could be likely implicated in the development of ARDS in this study, we present the first proteomics analysis of lung tissues using the iTRAQ approach, in which we identified a set of DEPs from the lungs of OA-treated and saline-treated mice. One study has demonstrated that intravenous injection of $\mathrm{OA}$ disrupts the endothelial barrier and causes severe lung edema [11]. In addition, the degree of abnormalities in coagulation and fibrinolysis proteins may strongly impact the outcomes of patients with ARDS [12]. Interestingly, the coagulation and complement pathways were among the top signaling pathways identified in this study. Moreover, it has been reported that antithrombin III (AT III), one upregulated component of the coagulation and complement pathways in our study, exhibits anti-inflammatory effect via decreasing the endothelial hyperpermeability of ALI in the animal models of burn and smoke inhalation [13]. Accordingly, we first validated the lung tissue expression levels of AT III by western blotting in OA- induced ALI, and then further confirmed the effect of AT III on OA -induced endothelial injury in human lung microvascular endothelial cells (HMVECs) by means of RNA interference technology. To further confirm the effect of AT III on OA -induced endothelial injury, human lung microvascular endothelial cells (HMVECs) were transfected with a specific siRNA against AT III. In our work, we found that the expression of AT III demonstrated by western blotting analysis were in accordance with that obtained using iTRAQ in the lung tissue, and knockdown of AT III exaggerated OAinduced endothelial cell integrity damage in HMVECs, suggesting that the expression levels and functional changes of AT III is related to OA-induced ALI. Our data showed that AT III may be a potential biomarker that could be likely implicated in the development of ARDS.

\section{Materials and Methods}

\section{Cell culture}

HMVECs were obtained from the Lonza (Walkersville, MD, USA). The HMVECs were grown in endothelial basal medium 2 (EBM 2) (Lonza) supplemented with endothelial growth medium SingleQuots and 5\% FBS (Gibco BRL, MO). HMVECs were maintained at $37^{\circ} \mathrm{C}$ in a humidified $5 \% \mathrm{CO}_{2}$ incubator.

\section{Animals}

Mice were purchased from the Shanghai SLAC Laboratory Animal Co. Ltd. and housed in a specific pathogen-free facility with 12 -h light/dark cycles and free access to food and water. All animal experiments and procedures were approved by the Institutional Animal Care and Use Committee of the Sixth People's Hospital Affiliated with Shanghai Jiao Tong University (SYXK [Shanghai, China] 2011-0128, 1 January 2011) and were conducted in accordance with the Guide for the Care and Use of Laboratory Animals published by the National Institutes of Health (No. 85-23, revised 1996, 1 January 1996). 


\section{Cellular Physiology Cell Physiol Biochem 2017;44:1949-1964

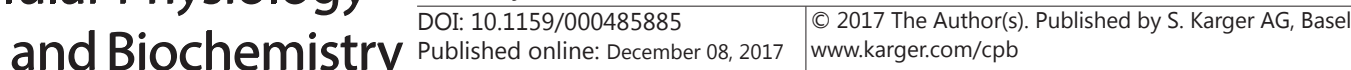

$\mathrm{Xu}$ et al.: Proteomics of OA-Induced ALI

\section{Animal model and grouping}

For OA-induced ALI, mice were injected with OA (200 $\mu \mathrm{L} / \mathrm{g}$, 01383, Sigma) via the tail vein. Mice treated with equal volumes of sterile saline served as the control group. The mice were killed 6 hours after OA administration. The perfused left lungs were cut into 5-um paraffin sections, followed by staining with hematoxylin-eosin (H\&E) for histological examination.

\section{Protein lysis, SDS-PAGE separation, digestion and iTRAQ labeling}

Protein lysis and SDS-PAGE separation. Lung tissues were frozen in liquid nitrogen and ground into powder using a glass homogenizer. The powder was resuspended and mixed with 5 volumes of TCA/acetone (1:9). The mixture was stored at $-20^{\circ} \mathrm{C}$ for $4 \mathrm{~h}$ and centrifuged at $6000 \mathrm{~g}$ for $30 \mathrm{~min}$ at $4{ }^{\circ} \mathrm{C}$. The supernatant was discarded, and the precipitate was washed three times with pre-cooled acetone. SDT buffer was added to the precipitate, and the sample was mixed and boiled for $5 \mathrm{~min}$. The lysate was collected, sonicated and boiled for an additional $15 \mathrm{~min}$. The supernatant was then centrifuged at $14000 \mathrm{~g}$ for $40 \mathrm{~min}$, followed by filtration through a $0.22-\mu \mathrm{m}$ filter. The filtrate was quantified using a BCA Protein Assay Kit (P0012, Beyotime), and the samples were stored at $-80{ }^{\circ} \mathrm{C}$ until further use. Next, $20 \mu \mathrm{g}$ of protein from each sample was mixed with loading buffer, boiled for $5 \mathrm{~min}$ and then separated on a 12.5\% SDS-PAGE gel. Protein bands were then visualized with Coomassie Blue R-250 staining.

Filter-aided sample preparation (FASP digestion). A 200- $\mu$ g aliquot of protein from each sample was added to $30 \mu \mathrm{L}$ of SDT buffer (4\% SDS, $100 \mathrm{mM}$ DTT, and $150 \mathrm{mM}$ Tris- $\mathrm{HCl}, \mathrm{pH}$ 8.0). The detergent, DTT and other low-molecular-weight components were then removed using UA buffer (8 M urea and $150 \mathrm{mM}$ Tris$\mathrm{HCl}, \mathrm{pH}$ 8.5) with repeated ultrafiltration (Sartorius, $30 \mathrm{kD}$ ). To block reduced cysteine residues, $100 \mu \mathrm{L}$ of iodoacetamide (100 mM IAA in UA buffer) was added, and the samples were incubated in the dark for 30 min. The filters were washed three times with $100 \mu \mathrm{L}$ of UA buffer, followed by two washes with $100 \mu \mathrm{L}$ of dissolution buffer (DS buffer). Finally, the protein suspensions were digested with $4 \mu \mathrm{g}$ of trypsin (Promega) in $40 \mu \mathrm{L}$ of DS buffer overnight at $37^{\circ} \mathrm{C}$, and the resulting peptides were collected as filtrate samples. Using UV light spectral density at $280 \mathrm{~nm}$ with an extinction coefficient of 1.1 , the peptide content of a $0.1 \%(\mathrm{~g} / \mathrm{L})$ solution was calculated based on the frequencies of tryptophan and tyrosine in vertebrate proteins.

iTRAQ labeling. A 100- $\mu$ g aliquot of peptide mixture from each sample was labeled using the iTRAQ reagent according to the manufacturer's instructions (Applied Biosystems, Milan, Italy). Briefly, pooled samples from the saline-treated mice were labeled with the 113,114, and 115 iTRAQ tags, whereas those from the OA-treated mice were labeled with the 116, 117, and 118 tags. The labeled peptide samples were incubated at room temperature for $1 \mathrm{~h}$ and then mixed at equivalent ratios. One machine repeat was added to control for the randomness of the experiment. The iTRAQ procedure was conducted twice for protein screening.

Peptide fractionation with reversed-phase (RP) chromatography

RP chromatography was performed to remove all interfering substances using the Agilent 1260 Infinity II HPLC Pump system. The vacuum-dried peptide mixture was reconstituted with buffer A (10 mM $\mathrm{HCOONH}_{4}, 5 \%$ ACN, pH 10.0) and loaded onto a $4.6 \mathrm{~mm} \mathrm{X} 100 \mathrm{~mm}$ XBridge Peptide BEH C18 column containing $5-\mu \mathrm{m}$ particles. The peptides were eluted at a flow rate of $1 \mathrm{~mL} / \mathrm{min}$ with a gradient of $0 \%-7 \%$ buffer A for $5 \mathrm{~min}, 7-40 \%$ buffer B (10 $\mathrm{mM} \mathrm{HCOONH}_{4}, 85 \%$ ACN, pH 10.0) for 5-40 min, 40\%-100\% buffer B for 45-50 min, and then $100 \%$ buffer B for 50-65 min. The elution was monitored by measuring the absorbance at $214 \mathrm{~nm}$, and fractions were collected every $1 \mathrm{~min}$ during the 5- to 50-min run period. The collected fractions were then dried via vacuum centrifugation.

LC-MS/MS and data analysis

LC-MS/MS analysis was performed on a Q Exactive mass spectrometer (Thermo Fisher Scientific) coupled to an Easy Nano Liquid Chromatography apparatus (nLC, Thermo Fisher Scientific). The peptide mixture was loaded onto a 15-cm Acclaim PepMap RSLC C18 reversed-phase analytical column (P/N164943; Thermo Fisher Scientific, San Jose, CA) in buffer A (0.1\% formic acid). The sample was loaded at $8 \mu \mathrm{L} / \mathrm{min}$ for $4 \mathrm{~min}$ and then was subjected to the following gradients: $300 \mathrm{~nL} / \mathrm{min}$ buffer B ( $80 \%$ acetonitrile, $0.1 \%$ formic acid), a linear gradient to buffer B for $5 \mathrm{~min}, 6-38 \%$ buffer B for $45 \mathrm{~min}, 38-100 \%$ buffer B for 5 min and a final hold in $100 \%$ buffer B for $5 \mathrm{~min}$. The mass spectrometer was operated in positive ion mode, and the MS data were obtained using a data-dependent top10 method that dynamically selected the most 
abundant precursor ions from the survey scan $(350-1800 \mathrm{~m} / \mathrm{z}$ ) for HCD fragmentation. The automatic gain control (AGC) target was set to $3 \mathrm{e} 6$, and the maximum injection time was set to $50 \mathrm{~ms}$. Survey scans were acquired at a resolution of 70, 000 at $200 \mathrm{~m} / \mathrm{z}$, the HCD spectra resolution was set to 17, 500 at $200 \mathrm{~m} / \mathrm{z}$, the isolation width was $2 \mathrm{~m} / \mathrm{z}$, and the normalized collision energy was $30 \mathrm{eV}$.

Data analysis. The MS/MS spectra were searched using the MASCOT engine (Matrix Science, London, UK; version 2.5) embedded in Proteome Discoverer 2.1. Next, we performed a bioinformatics analysis of the identified proteins, and DEPs were defined in the ITRAQ experiment according to the following criteria: unique peptides $\geq 1$, P-value $<0.05$, fold change $>1.2$ (or $<0.8333$ ). The DEPs were annotated using the Gene Ontology (GO) database (http://www.geneontology.org/), and protein classification was performed based on functional annotations using the GO terms for cellular components, biological processes and molecular functions. A Kyoto Encyclopedia of Genes and Genomes (KEGG) pathway analysis of the DEPs was conducted using the KEGG database (http://www.genome.jp/kegg/).

Verification of proteins by western blot analysis

The perfused lung tissues were homogenized in lysis buffer with a glass homogenizer. The lysates were centrifuged at $12,000 \mathrm{rpm}$ for $10 \mathrm{~min}$ at $4{ }^{\circ} \mathrm{C}$, and the supernatant was collected. The total protein concentration in the supernatant was quantified using a Pierce BCA protein assay kit. The protein extracts ( $50 \mu \mathrm{g} / \mathrm{sample}$ ) were loaded on $10 \%$ gels for electrophoresis before transfer to PVDF membranes. The membranes were blocked with $5 \%$ dry milk in Tris-buffered saline with $0.1 \%$ Tween-20 for $2 \mathrm{~h}$ and incubated with specific primary antibodies against AT III (1:200; sc-365194, Santa Cruz), 12-LO (1:200; sc-365194, Santa Cruz), DOCK2 (1:200; sc-365242, Santa Cruz), polycystin-2 (1:200; sc-47734, Santa Cruz), plasminogen (1:200; sc-376405, Santa Cruz) and ZO-1(1:200, ab59720, Abcam) overnight at $4{ }^{\circ} \mathrm{C}$, followed by incubation with a horseradish peroxidase-conjugated secondary antibody for $1 \mathrm{~h}$. The loading control was the constitutively expressed $\beta$-actin protein (1:5000; Hangzhou HuaAn Biotechnology Co. Ltd.). The blots were visualized using an enhanced chemiluminescence system.

\section{RNA interference and transfection}

AT III siRNA oligonucleotides were synthesized by GenePharma (Shanghai, China). The target sequences were as follows: siRNA-802: 5'-CGAAUCACCGAUGUCAUUCTT-3'; siRNA-854: 5'-UGCUGGUUAACACCAUUUATT-3'; and siRNA-919: 5'-AAGGAACUGUUCUACAAGGTT-3'. The sequence 5'-UUCUCCGAACGUGUCACGUTT- $3^{\prime}$ ' was used as a negative control siRNA. HMVECs were transfected with $100 \mathrm{nM}$ siRNA using Lipofectamine 2000 (Invitrogen) according to the manufacturer's instructions. siRNA knockdown was confirmed by western blot $72 \mathrm{~h}$ after transfection, and only the most effective siRNA species was used in the following study.

Enzyme-linked immunosorbent assay (ELISA)

HMVECs were transfected with AT III siRNA and control siRNA for $72 \mathrm{~h}$ and then treated with OA $(0.5 \mathrm{mmol} / \mathrm{L})$ for an additional $24 \mathrm{~h}$. The supernatants were collected for the measurement of IL-6, IL-1 $\beta$, TNF- $\alpha$ and TGF- $\beta$ concentrations by ELISA using commercially available ELISA kits (ExCell Biology, Inc., Shanghai, China). ELISA was performed according to the manufacturer's instructions. All samples from the AT III siRNA group and the control siRNA group were tested in triplicate.

\section{Immunofluorescence staining}

First, endothelial cells were plated on cover slips in 24 -well plates and pretreated with $0.5 \mathrm{mmol} / \mathrm{L} \mathrm{OA}$ for $24 \mathrm{~h}$. The cells were then fixed with $4 \%$ paraformaldehyde for $10 \mathrm{~min}$ at room temperature (RT). The cells were blocked in $2 \%$ BSA for $2 \mathrm{~h}$ at RT and incubated overnight with a primary antibody against ZO-1 (1:100; ab59720, Abcam). Secondary antibodies (1:200; goat anti-rabbit IgG [Alexa Fluor 594], ab150080) were from Abcam. F-actin was stained with phalloidin labeled with rhodamine (Sigma, USA), and nuclei were stained with the DNA-binding fluorescent dye DAPI (Beyotime) at RT. After staining, the cells were washed three times with PBST and analyzed using a fluorescence microscope (Olympus, Tokyo, Japan).

FITC-dextran transwell permeability assay

A previously described transwell permeability assay was used to determine the degree of HMEC monolayer permeability [14]. Briefly, after transfection with AT III siRNA or control siRNA, HMVECs were 
grown to confluency on matrigel-coated transwell inserts containing 3- $\mu \mathrm{m}$ pores (EMD Millipore) in a 24well plate. Twenty-four hours after plating, FITC-labeled dextran (3 kDa, Invitrogen) and OA were added to the lower chamber to final concentrations of $10 \mu \mathrm{g} / \mathrm{mL}$ and $0.5 \mathrm{mmol} / \mathrm{mL}$, respectively. Ten-microliter aliquots of medium were removed from the upper inserts, diluted in $90 \mu \mathrm{L}$ of water/well in a 96-well plate $60 \mathrm{~min}$ after treatment, and then analyzed for fluorescence intensity by fluorometry.

\section{Statistical analysis}

The data are expressed as the means \pm SD. A two-tailed Student's t-test was used to analyze differences between the two groups. P-values less than 0.05 were considered to indicate statistical significance.

\section{Results}

\section{Successful establishment of OA-induced ALI model and volcano plots of DEPS}

The histologic results indicated that lung tissues from OA-treated mice had massive inflammatory cell infiltration and fibrin deposition in the air space, thickened alveolar walls, edema, and formation of hyaline membranes compared with lung tissues from saline-treated mice. Based on the histologic and pathologic results, we determined that the OA-induced ALI model was well established (Fig. 1A).

Volcano plots were created using P-values ( $\log 10$ P-value) versus the log2 fold change in each protein to compare the level of significance and magnitude of change across the global proteomes of the lung tissues between two groups. The volcano plots illustrated that a large proportion of proteins were remarkably upregulated or downregulated in the lung tissues of the OA-treatment group compared with those in the lung tissues of the salinetreatment group (Fig. 1B).

\section{Identification of DEPS}

To verify the DEPs in OA-induced lung injury, total proteins from the lung tissues of the OA-treatment group and the saline-treatment group were extracted for ITRAQ analysis. In total, 5152 proteins were detected using iTRAQ. Compared with the saline group, the expression levels of 849 proteins were significantly different (upregulated $\geq 1.2$ fold or downregulated $\leq 0.84$ fold; $\mathrm{P} \leq 0.05$ ) in the $\mathrm{OA}$ group. Specifically, 545 of the 849 proteins were upregulated (Table 1), whereas the others were downregulated (Table 2). A hierarchical clustering heat map of the DEPs is shown in Fig. 2.

\section{GO analysis of DEPS}

The above DEPs were classified according to their biological processes, cellular components and molecular functions using the David database (Fig.

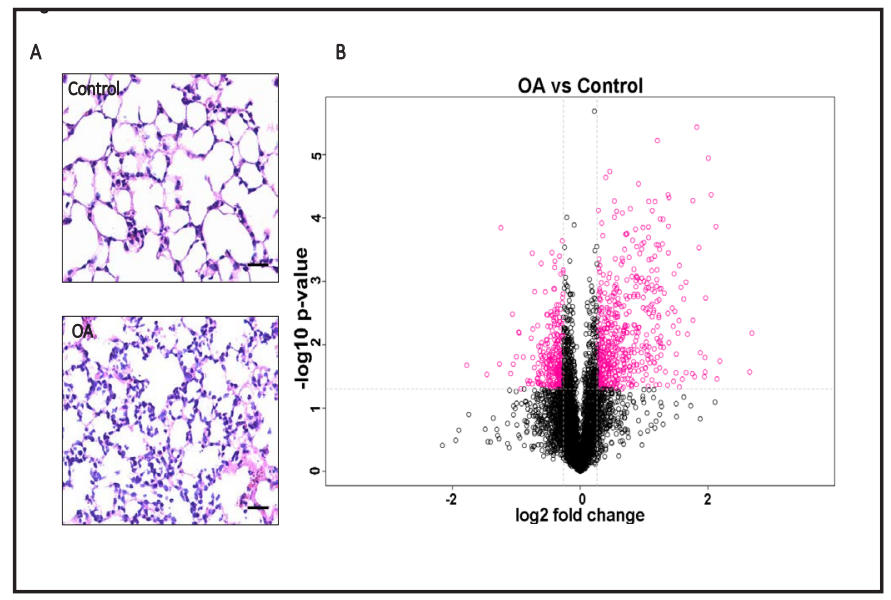

Fig. 1. Hematoxylin-eosin staining of lung tissues and volcano plots of differentially expressed proteins (DEPs). (A) Representative pathological and histological analyses of lung tissues from mice treated with $\mathrm{OA}$ and saline. (B) Volcano plot of quantified lung tissue proteins expressed in the OA-treatment group compared with those expressed in the saline-treatment (control) group. The $\mathrm{X}$-axis indicates $\log 2$-fold changes in up- (positive values) and downregulated (negative values) proteins. The Y-axis represents P-values in the form of - $\log 10$; smaller numerical values indicate higher P-values and lower credibility. Therefore, the pink dots in the top left quadrants represent downregulated proteins, and the pink dots in the top right quadrants represent upregulated proteins.

\section{KARGER}




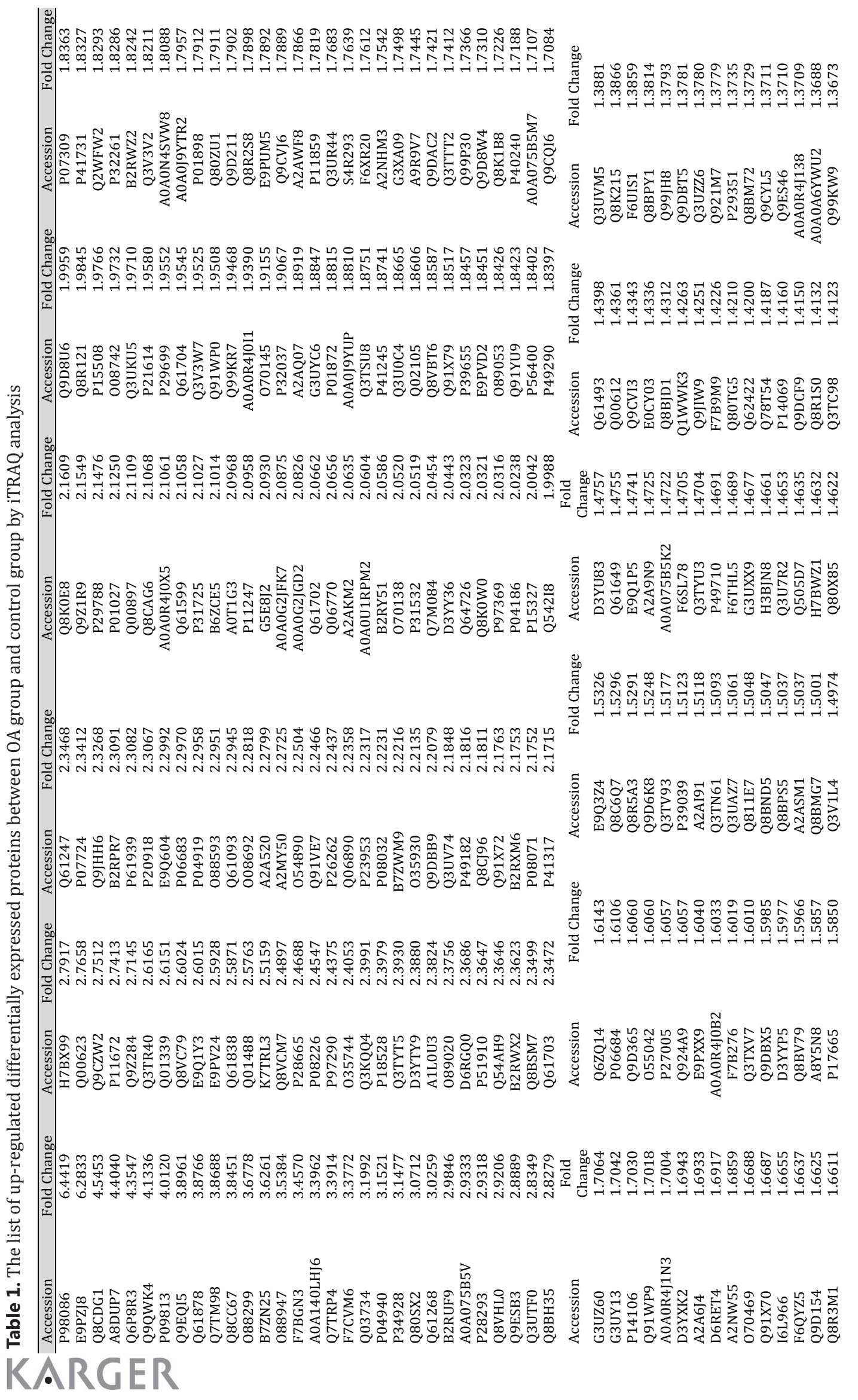




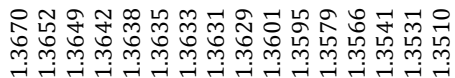

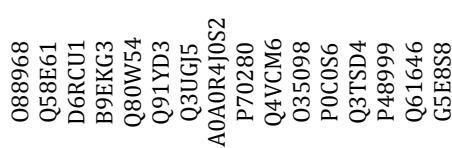

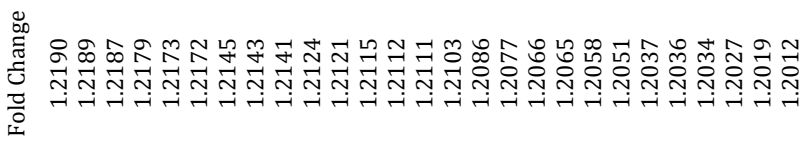

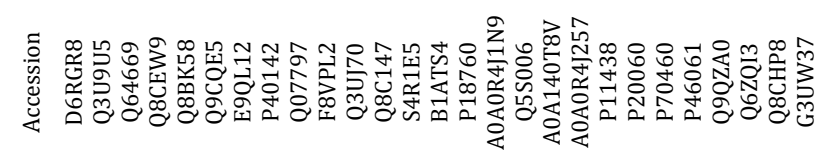

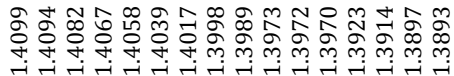

ฮี

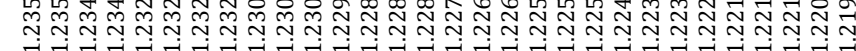

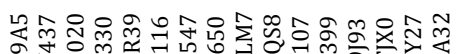
훙

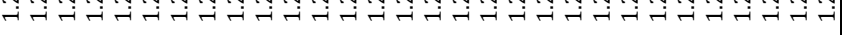

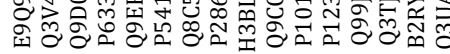

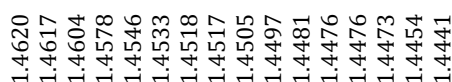

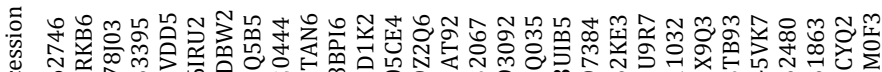

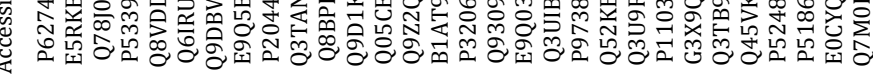

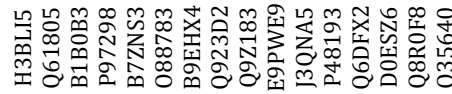

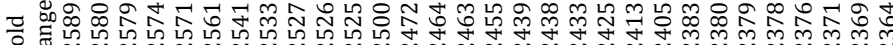

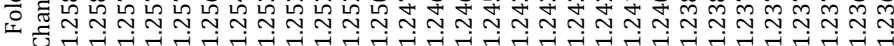

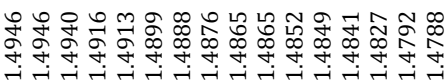

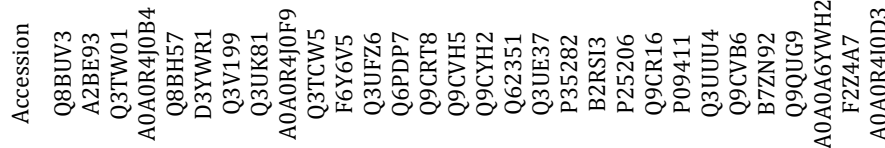

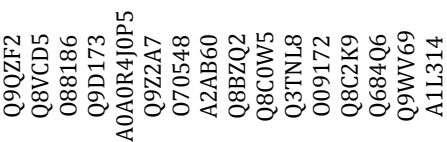

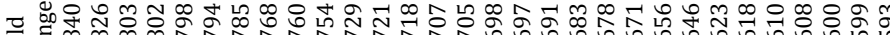

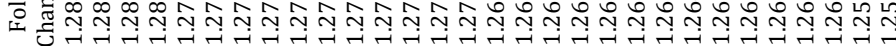

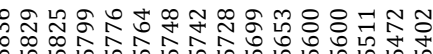

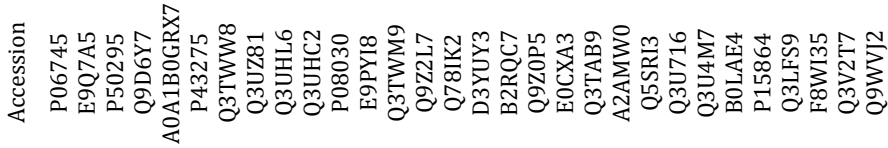

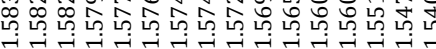

동

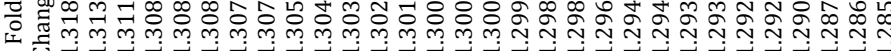

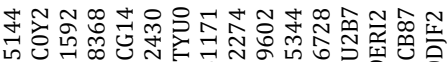

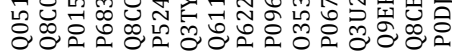

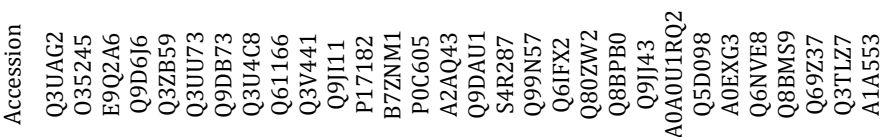

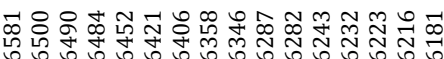

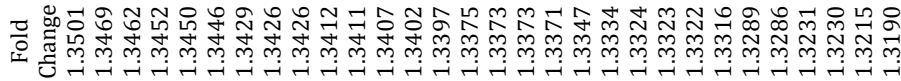




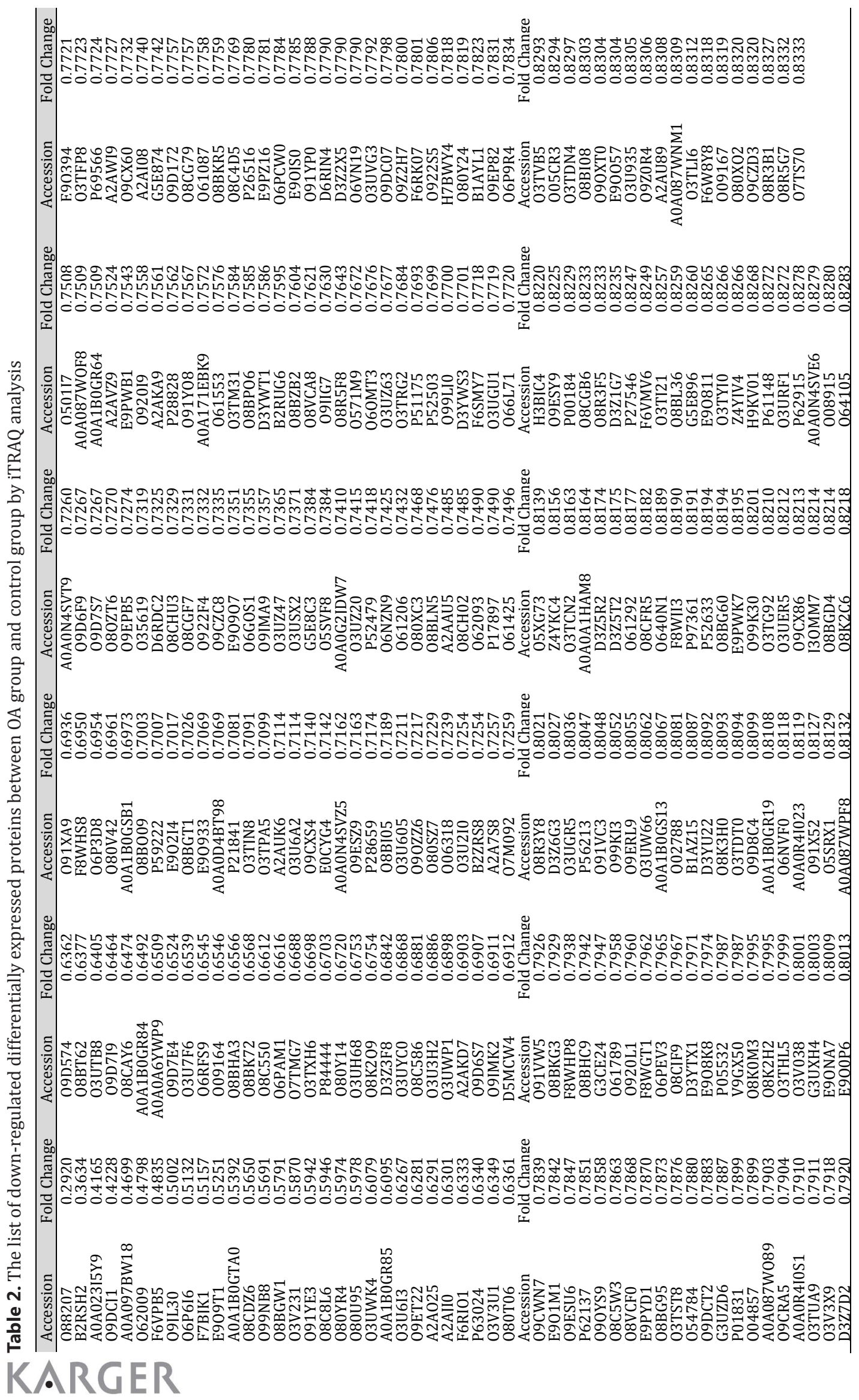


3). As shown in Fig. 4, the enriched GO terms (top 20) revealed that the proteins of interest were involved in the following areas or processes: extracellular region, extracellular space, extracellular region part, immune system, protein activation cascade, blood microparticle system, overall immune response, humoral immune response, protein-lipid complexes, lipoprotein particles, plasma lipoprotein particles, regulation of plasma lipoprotein particle levels, defense response, wound healing response, regulation of wound healing, positive regulation of responses to stimuli, plasma lipoprotein particle organization, protein-lipid complex subunit organization, and peptidase inhibitor activity.
Fig. 2. Heat map of differentially expressed proteins (DEPs) in lung tissue from OA-treated and control mice. Cluster map comparing the protein expression patterns of OA-treatment and control groups. Blue represents lower protein expression levels than, red represents higher expression levels than, and white indicates the same expression levels as those in the control. The color scale shown at the lower right indicates the fold changes in protein expression of all the samples.

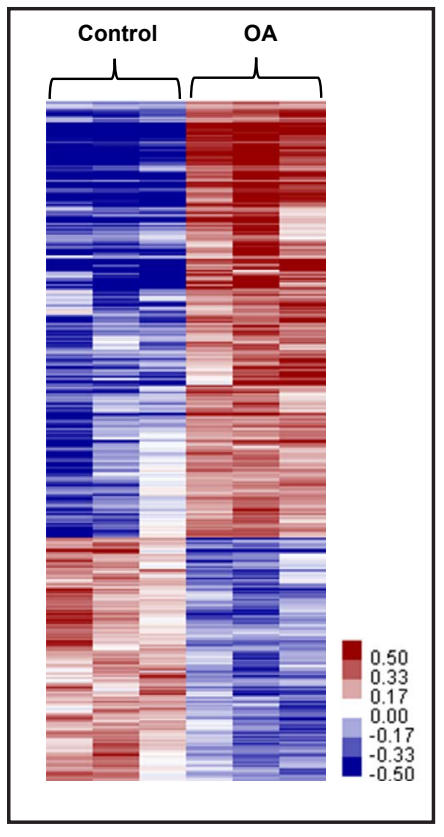

\section{KEGG pathway analysis of DEPs}

A KEGG pathway map was applied to determine the pathways related to these DEPs. The top 20 KEGG pathways are listed in Fig. 5. The results of the KEGG analysis showed that the

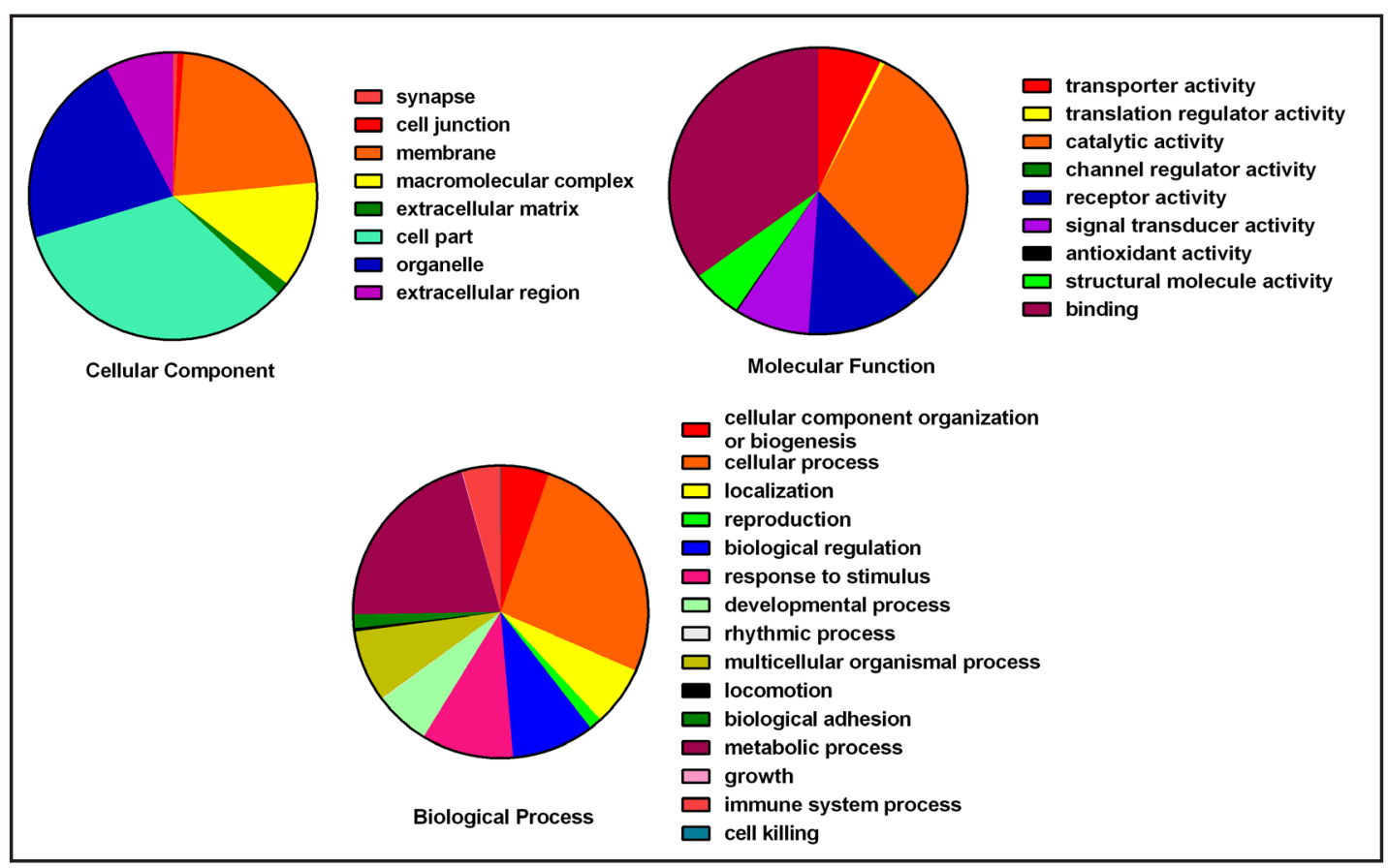

Fig. 3. Gene ontology (GO) annotation of differentially expressed proteins (DEPs). All identified proteins were functionally annotated in the GO database according to their cellular component (A), molecular function (B) and biological process (C). Most of the proteins with differential abundance levels analyzed for cellular component, molecular function and biological process were associated with cell parts, binding, and cell processes, respectively. 
complement and coagulation cascade pathways were the predominant processes associated with the DEPs. The cytokine-cytokine receptor interaction and ECM-receptor interaction pathways were also identified.

\section{Western blot validation}

Based on the KEGG pathway and fold change analyses, the lung expression levels of AT III, 12-LO, DOCK2, polycystin-2 and plasminogen were selected for further validation. The results showed that the expression levels of these DEPs were remarkably increased in the OA-treatment group compared with those in the control group (Fig. 6A). In addition, in HMVECs exposed to $0.5 \mathrm{mmol} / \mathrm{L} \mathrm{OA}$, AT III expression was significantly enhanced in the OA-treatment group compared with that in the control group (Fig. 6B). The quantification of the verified proteins was highly inconsistent with the proteomic results. However, the roles and mechanisms of these upregulated proteins in OA-induced lung injury remain poorly understood. Previous studies have shown that the primary pathogenesis of sepsis involves the initiation of the coagulation cascade, followed by pro-inflammatory cytokine production [15]. Satoshi Hagiwara also reported that AT III suppressed LPS-induced activation of the

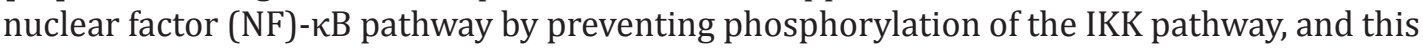
may possibly inhibit the secretion of HMGB1 and improve endotoxin-induced ALI in rats [16].

\section{AT III knockdown increases cytokine secretion}

To further elucidate the role of AT III in OA-induced endothelial inflammation and integrity, we utilized a specific siRNA to silence AT III expression. AT III knockdown was validated by western blot analysis of whole-cell lysates from non-specific (control) siRNAand AT III-specific siRNA-transfected endothelial cells. As shown in Fig. 7A, the knockdown effect of AT III siRNA-919 was the most effective; therefore, this siRNA was used in the following study. To detect the effects of AT III on the release of inflammatory factors in OA-

Fig. 4. Gene ontology (GO) enrichment analysis. The GO terms of most significantly differentially expressed proteins (DEPs) identified from the comparison between the OA-treatment and control groups were mainly enriched in the extracellular region, followed by the extracellular region part and immune system processes.

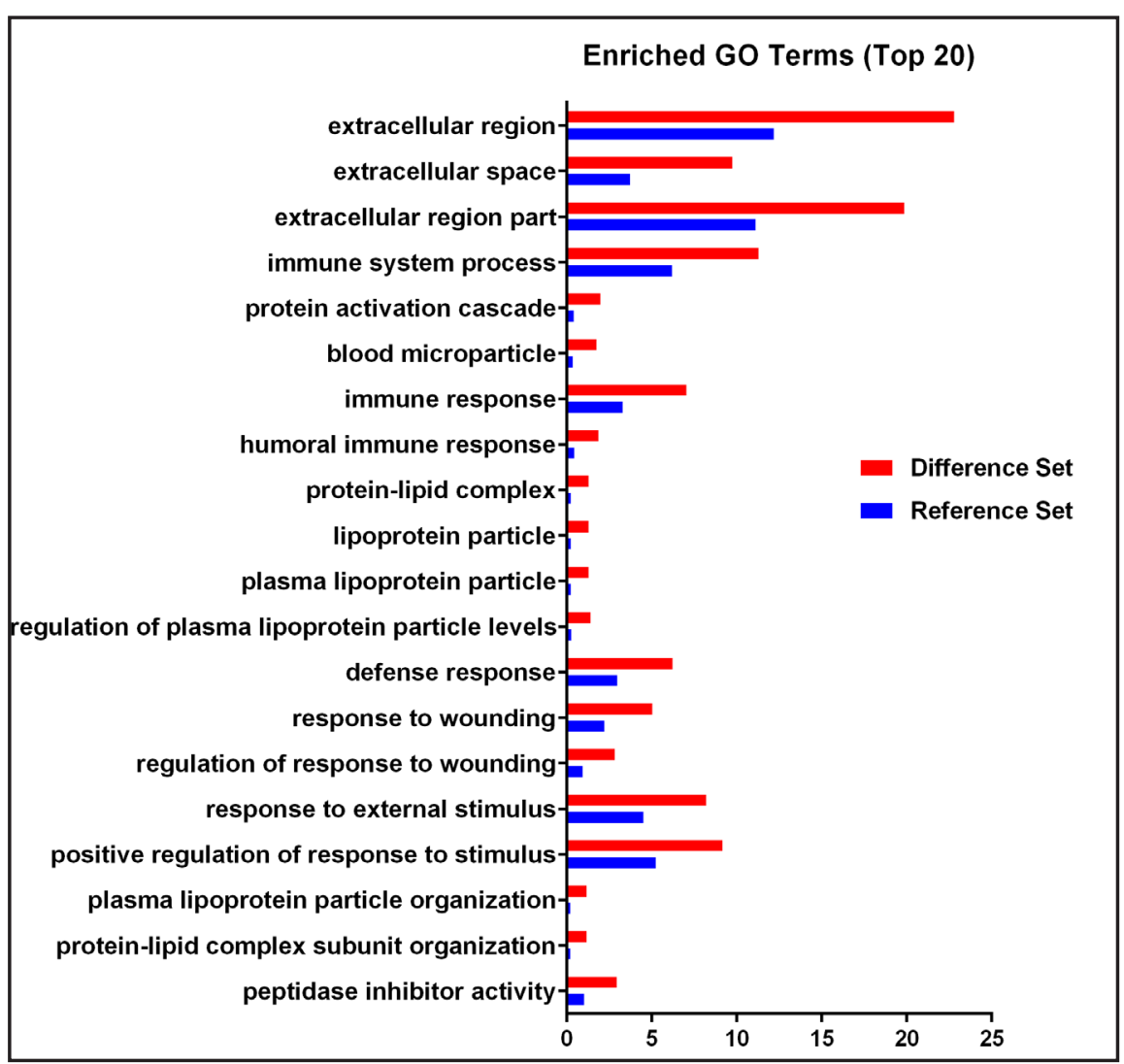


treated endothelial cells, culture supernatants from HMVECs that had been transfected with AT III siRNA or control siRNA and then treated with OA were collected, centrifuged and subjected to IL-6, IL-1 $\beta$, TNF- $\alpha$ and TGF- $\beta$ ELISA. Compared with the control siRNA group, the levels of IL-6, IL-1 $\beta$, TNF- $\alpha$ and TGF- $\beta$ in the culture supernatants were significantly increased $24 \mathrm{~h}$ after the administration of OA in the AT III siRNA group (Fig. 7B, 7C, 7D and $7 \mathrm{E}$; $\mathrm{P}<0.05$ ), which suggested that knockdown of AT III increased cytokine secretion in OAstimulated endothelial cells.

\section{AT III knockdown impairs endothelial integrity}

Endothelium intracellular junctions, such as endothelial tight junctions and adherent junctions, maintain the barrier function of the endothelium and regulate endothelial cell contraction $[17,18]$. Endothelial hyperpermeability is specifically caused by cell junction breakdown, which ultimately leads to the formation of intracellular gaps [19]. Endothelial tight junctions are composed of the tetraspan transmembrane proteins claudin and occludin, the latter of which maintains the integrity of the endothelium in the blood-brain barrier [20]. Adherens junctions maintain the mechanical strength of intracellular adhesion by homophilic $\mathrm{Ca}^{2+}$-dependent trans-interactions with VE-cadherin [21]. Both endothelial tight junctions and adherens junctions interact with the cortical actin cytoskeleton through adaptor molecules, such as the tight junction components ZO-1, -2, and -3 and the catenin family members $\alpha-, \beta$-, and $\gamma$-catenin [22]. In this study, the expression of the tight junction protein Z0-1 was markedly decreased (Fig. 8A), whereas the expression of the stress fiber F-actin (Fig. 8B) was significantly increased in the AT III siRNA group compared with that in the control siRNA group. Additionally, endothelial cell integrity was examined using a FITC-dextran transwell permeability assay. (Fig. 8C) In this assay, which monitors the passage of a small molecule, FITC-labeled dextran, through endothelial cells on matrigel-coated transwell inserts containing $3-\mu \mathrm{m}$ pores, we found that FITC-labeled dextran permeability

Fig. 5. KEGG pathway analysis of differentially expressed proteins (DEPs). The most highly enriched pathways were the complement and coagulation cascade pathways, followed by Fc gamma R-mediated phagocytosis and amoebiasis.

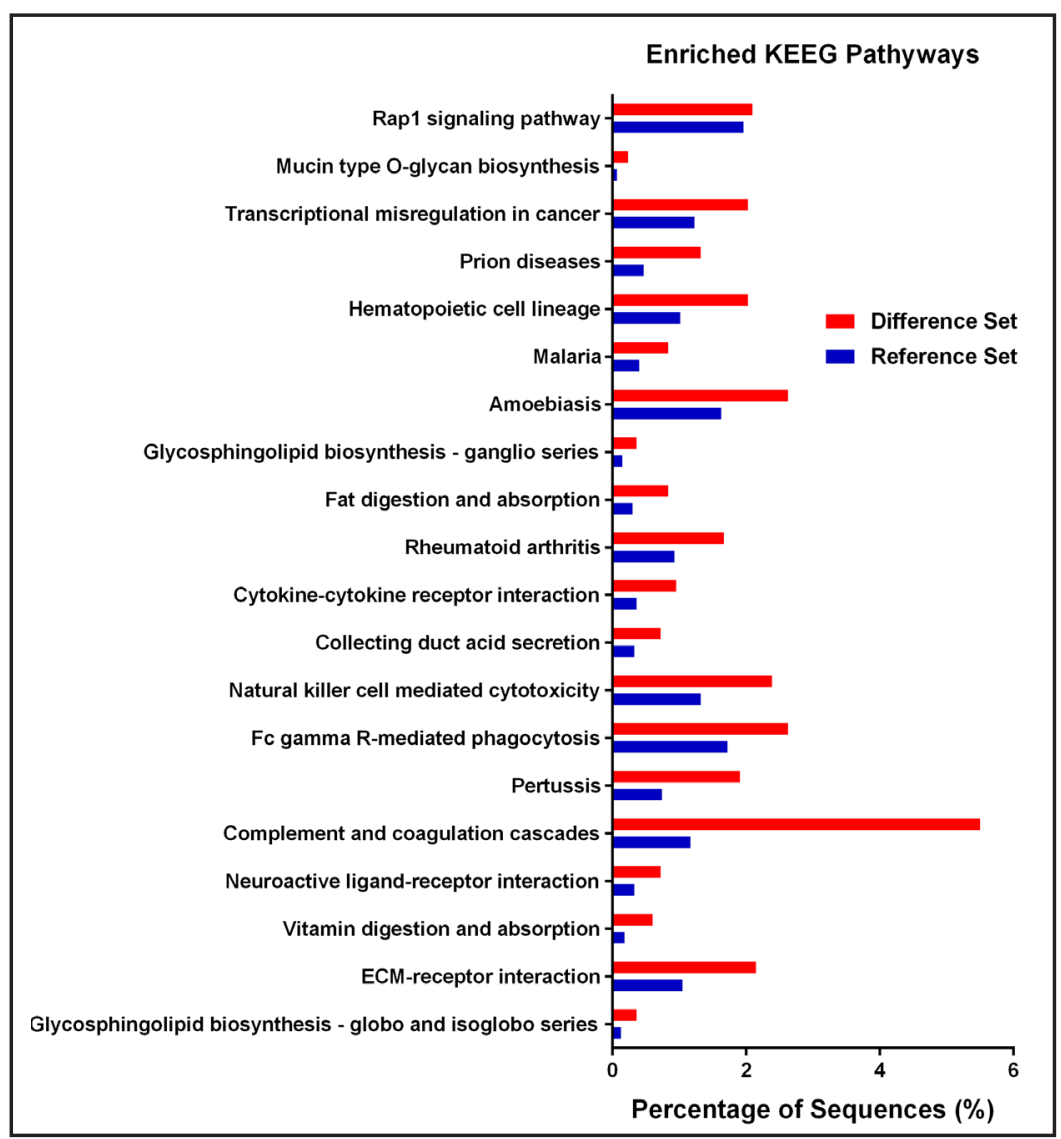


was markedly increased in the AT III siRNA group compared with that in the control siRNA group $(\mathrm{P}<0.05)$, suggesting that AT III knockdown increased endothelial cell permeability. In addition, compared with the control group, the expression of phosphorylated myosin light chain (pMLC) was notably increased in the AT III siRNA group (Fig. 8D).

\section{Discussion}

This study represents the first-ever investigation of lung tissue proteomic profiles from mice with OA-induced ALI using iTRAQ and nano-LC-MS/MS techniques to detect potential biomarkers and elucidate the molecular alterations that occur following lung injury. Interestingly, we identified and quantified lung tissue proteins that were differentially expressed in the OA-treatment group mice compared with those in the saline-treatment group.

Although the exact mechanisms by which abnormalities in coagulation and fibrinolysis proteins contribute to patient outcomes in ALI are not well established, a previous study indicated that coagulation and the inflammatory cascade may affect the pathogenesis of ALI and ARDS [12]. Some experimental evidence has revealed that abnormalities in the pro-coagulation and fibrinolysis protein pathways are features of ALI $[23,24]$. ALI is accompanied by fibrin deposition in the lung and increased plasminogen activator inhibitor expression in bronchoalveolar lavage (BAL) fluid.

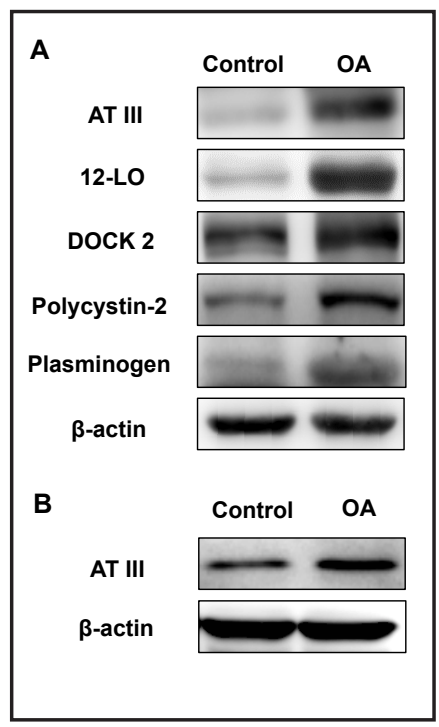

Fig. 6. Confirmation of differentially expressed proteins (DEPs) by western blot. (A) Immunoblotting analysis of proteins (AT III, 12- LO, DOCK2, polycystin-2 and plasminogen) in OA-treated and control mice. (B) Immunoblotting analysis of AT III protein in HMVECs. The $\beta$-actin protein was used as a control. Intriguingly, by applying the ITRAQ approach to identify

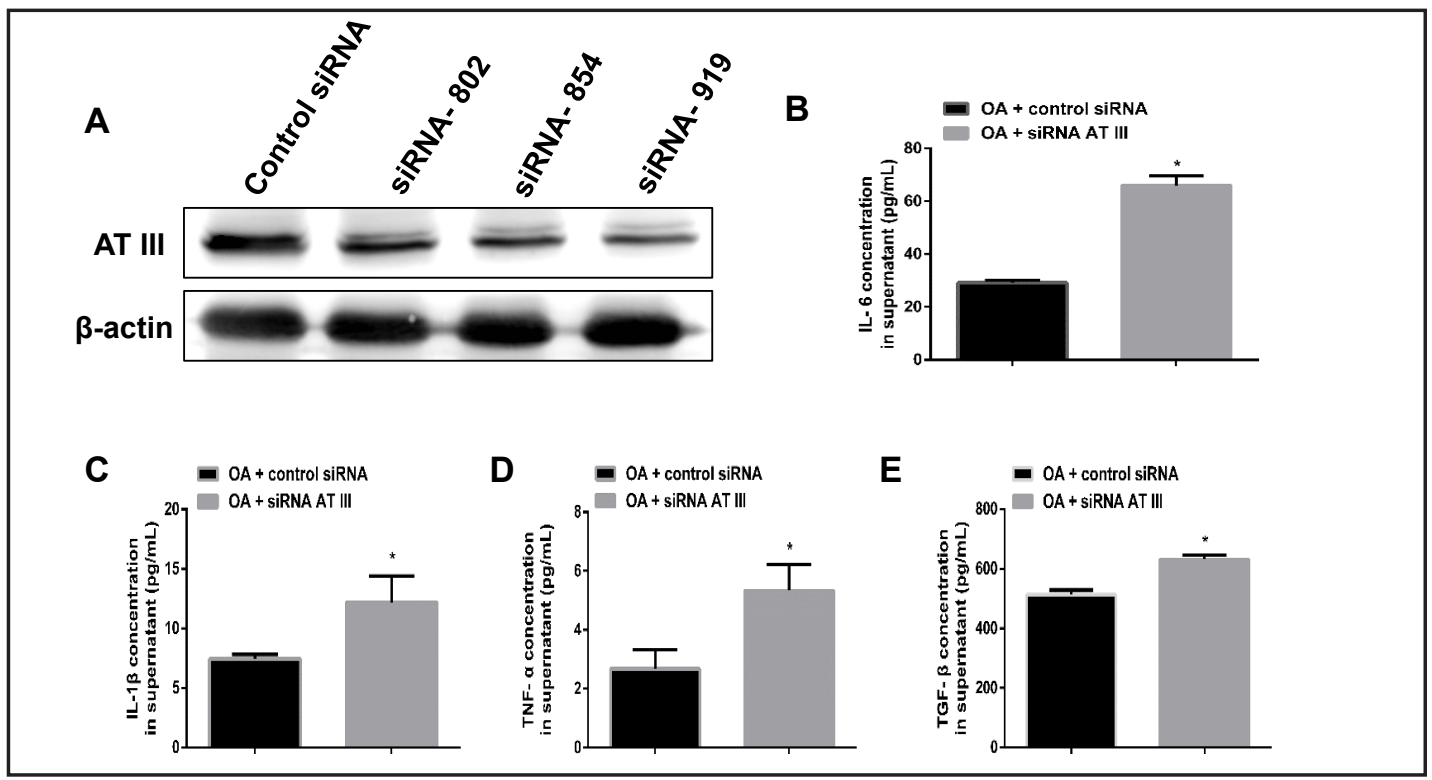

Fig. 7. Changes in inflammatory factor levels determined by ELISA. (A) AT III knockdown was validated by western blotting of whole-cell lysates from non-specific (control) siRNA- and AT III-specific siRNA-transfected endothelial cells. HMVECs were transfected with non-specific RNA or AT III-specific siRNA duplexes, followed by treatment with OA or saline for $24 \mathrm{~h}$. (B, C, D, E) After $24 \mathrm{~h}$ of OA stimulation, the supernatants from siRNA-transfected HMVECs were collected and centrifuged to remove cell debris. The concentrations of IL-6, IL-1 $\beta$, TNF- $\alpha$ and TGF- $\beta$ were detected via ELISA $(\mathrm{P}<0.05)$. 
Fig. 8. Effects of AT III knockdown on endothelial integrity. (A) The expression of ZO-1 in endothelial cells treated with control siRNA and AT III-specific siRNA, followed by stimulation with $0.5 \mathrm{mmol} / \mathrm{L}$ $\mathrm{OA}$, was confirmed by western blotting. Equal protein loading was detected by membrane reprobing with a $\beta$-actin antibody. (B) After siRNA transfection, followed by stimulation with $0.5 \mathrm{mmol} / \mathrm{L}$ $\mathrm{OA}$, endothelial cells cultured on 24-well glass coverslips were subjected to immunofluoresence staining for F-actin. Bar $=50 \mu \mathrm{m}$. (C) FITC-dextran transwell permeability assay to observe the degree

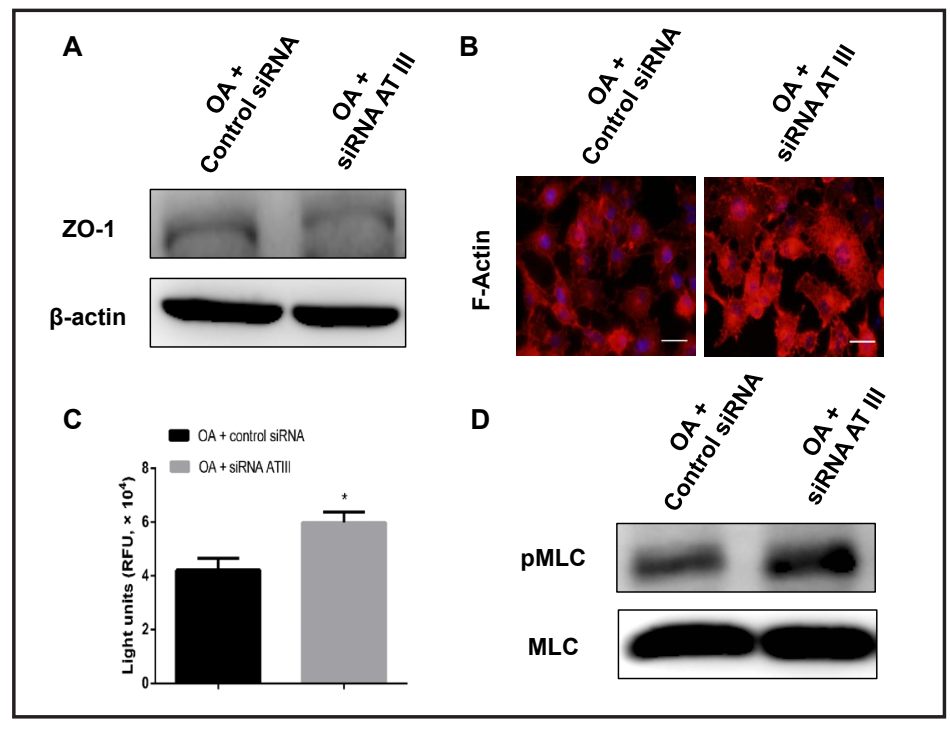
of HMVECs monolayer permeability ( $\mathrm{P}<0.05$ compared with the control group). (D) The expression of pMLC in HMVECs treated with control siRNA and AT III-specific siRNA, followed by stimulation with OA, was validated by western blotting. Equal loading was confirmed by reprobing with anti-total MLC antibody.

relevant KEGG pathways, we found that the coagulation and complement pathways were among the top signaling pathways identified in the present study.

One upregulated component of the coagulation and complement pathways was AT III. AT III, encoded by SerpinC1, is an important anti-coagulation molecule and serine protease inhibitor in the coagulation cascade [25, 26]. Moreover, there is evidence demonstrating that AT III exerts anti-inflammatory effects, at least partially, by increasing the level of PGI 2, suppressing NF- $\kappa B$, decreasing leucocyte-endothelial interactions, and inhibiting microvascular leakage [27-31]. Wang et al. [32] noted that SerpinC1 insufficiency aggravated renal ischemia/reperfusion injury by increasing renal oxidative stress, tubular apoptosis, and macrophage infiltration. Nevertheless, continuous infusion of rhAT III attenuated neutrophil activation, adhesion and transendothelial migration and thereby reduced endothelial hyperpermeability of ALI following burn and smoke inhalation in animal models [13]. The potential mechanism of action may be the interaction between rhAT III with the syndecan-4 receptor on endothelial cells and neutrophils. Using in vivo and in vitro experiments, we confirmed that AT III was upregulated in the OA-treatment group compared with that in the saline-treatment group. To further identify the role of AT III in OA-induced inflammatory responses, we utilized AT III-targeted siRNA. We found that AT III knockdown exaggerated OA-induced inflammatory responses, as demonstrated by increased production of inflammatory cytokines, such as IL- 6 , IL-1 $\beta$, TNF- $\alpha$ and TGF- $\beta$.

From an analysis of the coagulation and complement signaling pathways, we observed that AT III is associated with not only inflammatory responses but also endothelial permeability. It has been reported that intravenous injection of OA has a direct toxic effect on vascular endothelium within minutes, which leads to permeability edema [33, 34]. In this study, we also found that FITC-labeled dextran permeability markedly increased in the AT III knockdown group compared with that in the control siRNA group. It is well known that cellular tight junctions are critical for the stabilization of endothelial barrier function. Z0-1, which plays a crucial role in forming tight junctions, also regulates angiogenesis and endothelial barrier formation [35-38]. Using in vitro experiments, we determined that when endothelial cells were exposed to OA, the expression of ZO-1 was decreased in the control siRNA group, and this effect was further exacerbated in the AT III siRNA group. In addition, cytoskeletal F-actin stress fibers possibly lead to pulmonary endothelial hyperpermeability. Some evidence has indicated that regulation of F-actin stress fiber formation is partially 
associated with endothelial barrier function, but the exact mechanism underlying this process is poorly understood [39]. Our results illustrated that AT III knockdown enhanced the formation of F-actin stress fibers in endothelial cells exposed to OA. These findings suggest that AT III has a protective role in endothelial cell permeability, possibly via interactions with ZO-1 and the F-actin cytoskeleton.

Dudek et al. [40,41] showed that thrombin induced disruption of the endothelial barrier, which caused physiological dysfunction such as hypoxemia, atherosclerosis, and pulmonary edema, a typical characteristic of ALI. Van Hinsbergh et al. [42] noted that the possible mechanism of histamine-induced transient short-term hyperpermeability involved $\mathrm{Ca}^{2+} /$ calmodulin-dependent activation of the myosin light chain (MLC) kinase. The cause of thrombin-induced endothelial hyperpermeability involved activation of the small GTPase RhoA and Rho kinase, which increased the phosphorylation of MLC. In addition, Parker et al. [43] demonstrated that thrombin induced endothelial barrier destabilization, at least partly, by inhibiting the activation of Rap1 and Rac1 and increasing the phosphorylation and distribution of VE-cadherin, the phosphorylation of MLC, and actin polymerization. Consistent with the results of previous studies, we observed that after endothelial cells were exposed to $0.5 \mathrm{mmol} / \mathrm{L} \mathrm{OA}$, the expression of pMLC was increased in the AT III siRNA group compared with that in the control siRNA group.

In short, AT III knockdown exaggerated OA-induced inflammatory responses, as demonstrated by increased production of inflammatory cytokines, such as IL-6, IL-1 $\beta$, TNF- $\alpha$ and TGF- $\beta$; enhancement of endothelial hyperpermeability, as indicated by increased passage of FITC-labeled dextran and phosphorylation of MLC; decreased expression of ZO-1; and increased expression of F-actin stress fibers.

The present study demonstrated that most of the verified DEPs may serve as therapeutic targets for ALI. For instance, after endothelial cells were exposed to OA, we observed that the expression of AT III increased in vivo and in vitro, whereas AT III knockdown exaggerated inflammatory responses and endothelial integrity dysfunction. We think that, to some degree, AT III may attenuate endothelial hyperpermeability and further maintain end othelial integrity during thrombin-induced disruption of endothelial barrier function. In future studies, we will focus on identifying the relationship between these proteins and the pathogenesis of OA-induced ALI to provide guidelines for treating patients with ALI.

\section{Acknowledgements}

This work was supported by grants from the National Natural Science Foundation of China (81272147 to AZ Wang) and the Suitable Technology Extension Program of Shanghai Health and Family Planning Commission (2013SY031 to AZ Wang).

\section{Disclosure Statement}

We declare that we have no financial or commercial conflicts of interest.

\section{References}

1 Ferguson ND, Fan E, Camporota L, Antonelli M, Anzueto A, Beale R, Brochard L, Brower R, Esteban A, Gattinoni L, Rhodes A, Slutsky AS, Vincent JL, Rubenfeld GD, Thompson BT, Ranieri VM: The berlin definition of ards: An expanded rationale, justification, and supplementary material. Intensive Care Med 2012;38:1573-1582.

$\rightarrow 2$ Ji Y, Gao F, Sun B, Hao J, Liu Z: Angiotensin-converting enzyme 2 inhibits apoptosis of pulmonary endothelial cells during acute lung injury through suppressing smad2 phosphorylation. Cell Physiol Biochem 2015;35:2203-2212. 


\section{Cellular Physiology Cell Physiol Biochem 2017;44:1949-1964 \begin{tabular}{l|l|l} 
and Biochemistry Published onlIne: December 08, 2017 & $\begin{array}{l}\text { (c) } 2017 \text { The Author(s). Published by S. Karger AG, Basel } \\
\text { www.karger.com/cpb }\end{array}$
\end{tabular}}

- Y Yin X, Liang Z, Yun Y, Pei L: Intravenous transplantation of bmp2-transduced endothelial progenitor cells attenuates lipopolysaccharide-induced acute lung injury in rats. Cell Physiol Biochem 2015;35:2149-2158.

4 Yu X, Lin Q Qin X, Ruan Z, Zhou J, Lin Z, Su Y, Zheng J, Liu Z: Ace2 antagonizes vegfa to reduce vascular permeability during acute lung injury. Cell Physiol Biochem 2016;38:1055-1062.

$5 \mathrm{Xu}$ S, Xu M, Li GG, Wang C, Song H, Bai J: Early recruitment of il-10-producing b cells into alveoli improved the resolution of acute lung injury. Cell Physiol Biochem 2016;38:1752-1760.

6 Karmpaliotis D, Kosmidou I, Ingenito EP, Hong K, Malhotra A, Sunday ME, Haley KJ: Angiogenic growth factors in the pathophysiology of a murine model of acute lung injury. Am J Physiol Lung Cell Mol Physiol 2002;283:L585-595.

7 Zhang HX, Liu SJ, Tang XL, Duan GL, Ni X, Zhu XY, Liu YJ, Wang CN: H2s attenuates lps-induced acute lung injury by reducing oxidative/nitrative stress and inflammation. Cell Physiol Biochem 2016;40:1603-1612.

8 Chen Y, Wang L, Kang Q, Zhang X, Yu G, Wan X, Wang J, Zhu K: Heat shock protein a12b protects vascular endothelial cells against sepsis-induced acute lung injury in mice. Cell Physiol Biochem 2017;42:156-168.

-9 Niu R, Liu Y, Zhang Y, Zhang Y, Wang H, Wang Y, Wang W, Li X: Itraq-based proteomics reveals novel biomarkers for idiopathic pulmonary fibrosis. PloS one 2017;12:e0170741.

10 Hirsch J, Niemann CU, Hansen KC, Choi S, Su X, Frank JA, Fang X, Hirose R, Theodore P, Sapru A, Burlingame $\mathrm{AL}$, Matthay MA: Alterations in the proteome of pulmonary alveolar type ii cells in the rat after hepatic ischemia-reperfusion. Crit Care Med 2008;36:1846-1854.

11 Tao W, Miao QB, Zhu YB, Shu YS: Inhaled neutrophil elastase inhibitor reduces oleic acid-induced acute lung injury in rats. Pulm Pharmacol Ther 2012;25:99-103.

12 Ware LB, Matthay MA, Parsons PE, Thompson BT, Januzzi JL, Eisner MD: Pathogenetic and prognostic significance of altered coagulation and fibrinolysis in acute lung injury/acute respiratory distress syndrome. Crit Care Med 2007;35:1821-1828

-13 Rehberg S, Yamamoto Y, Sousse LE, Jonkam C, Zhu Y, Traber LD, Cox RA, Prough DS, Traber DL, Enkhbaatar P: Antithrombin attenuates vascular leakage via inhibiting neutrophil activation in acute lung injury. Crit Care Med 2013;41:e439-446.

14 Martins-Green M, Petreaca M, Yao M: An assay system for in vitro detection of permeability in human “endothelium". Methods Enzymol 2008;443:137-153.

15 Iba T, Kidokoro A, Yagi Y: The role of the endothelium in changes in procoagulant activity in sepsis. J Am Coll Surg1998;187:321-329.

16 Hagiwara S, Iwasaka H, Matsumoto S, Noguchi T: High dose antithrombin iii inhibits HMGB1 and improves endotoxin-induced acute lung injury in rats. Intensive Care Med 2008;34:361-367.

17 Franke WW: Discovering the molecular components of intercellular junctions--a historical view. Cold Spring Harb Perspect Biol 2009;1:a003061.

18 Bazzoni G, Dejana E: Endothelial cell-to-cell junctions: Molecular organization and role in vascular homeostasis. Physiol Rev 2004;84:869-901.

19 Aird WC: Phenotypic heterogeneity of the endothelium: I. Structure, function, and mechanisms. Circ Res 2007;100:158-173.

-20 Lee WLA, Michael-Titus AT, Shah DK: Hypoxic-ischaemic encephalopathy and the blood-brain barrier in neonates. Dev Neurosci 2017;39:4-58.

-21 Giannotta M, Trani M, Dejana E: VE-cadherin and endothelial adherens junctions: Active guardians of vascular integrity. Dev Cell 2013;26:441-454.

-22 Schnittler H: Contraction of endothelial cells: 40 years of research, but the debate still lives. Histochem Cell Biol 2016;146:651-656.

23 Frantzeskaki F, Armaganidis A, Orfanos SE: Immunothrombosis in acute respiratory distress syndrome: Cross talks between inflammation and coagulation. Respiration 2017;93:212-225.

-24 Ozolina A, Sarkele M, Sabelnikovs O, Skesters A, Jaunalksne I, Serova J, Ievins T, Bjertnaes LJ, Vanags I: Activation of coagulation and fibrinolysis in acute respiratory distress syndrome: A prospective pilot study. Front Med 2016;3:64-73.

25 Zhao Q, Yin J, Lu Z, Kong Y, Zhang G, Zhao B, Wang F: Sulodexide protects contrast-induced nephropathy in sprague-dawley rats. Cell Physiol Biochem 2016;40:621-632.

26 Lu Z, Wang F, Liang M: Serpinc1/antithrombin iii in kidney-related diseases. Clin Sci (Lond) 2017;131:823831. 


\section{Cellular Physiology Cell Physiol Biochem 2017;44:1949-1964

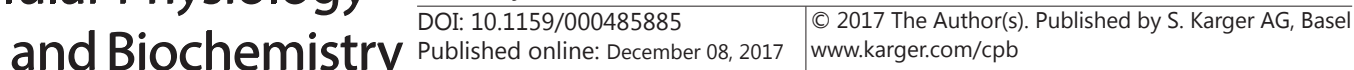

$\mathrm{Xu}$ et al.: Proteomics of OA-Induced ALI

27 Mizutani A, Okajima K, Uchiba M, Isobe H, Harada N, Mizutani S, Noguchi T: Antithrombin reduces ischemia/reperfusion-induced renal injury in rats by inhibiting leukocyte activation through promotion of prostacyclin production. Blood 2003;101:3029-3036.

28 Oelschlager C, Romisch J, Staubitz A, Stauss H, Leithauser B, Tillmanns H, Holschermann H: Antithrombin III inhibits nuclear factor kappab activation in human monocytes and vascular endothelial cells. Blood 2002;99:4015-4020.

-29 Mansell A, Reinicke A, Worrall DM, O’Neill LA: The serine protease inhibitor antithrombin III inhibits LPSmediated NF-кB activation by TLR-4. FEBS Lett 2001;508:313-317.

-30 Souter PJ, Thomas S, Hubbard AR, Poole S, Romisch J, Gray E: Antithrombin inhibits lipopolysaccharideinduced tissue factor and interleukin- 6 production by mononuclear cells, human umbilical vein endothelial cells, and whole blood. Crit Care Med 2001;29:134-139.

-31 Dunzendorfer S, Kaneider N, Rabensteiner A, Meierhofer C, Reinisch C, Romisch J, Wiedermann CJ: Cellsurface heparan sulfate proteoglycan-mediated regulation of human neutrophil migration by the serpin antithrombin III. Blood 2001;97:1079-1085.

-32 Wang F, Zhang G, Lu Z, Geurts AM, Usa K, Jacob HJ, Cowley AW, Wang N, Liang M: Antithrombin III/Serpinc1 insufficiency exacerbates renal ischemia/reperfusion injury. Kidney Int 2015;88:796-803.

33 Gil Cano A, Gracia Romero M, Monge Garcia MI, Guijo Gonzalez P, Ruiz Campos J: Preemptive hemodynamic intervention restricting the administration of fluids attenuates lung edema progression in oleic acidinduced lung injury. Med Intensiva 2017;41:135-142.

-34 Haque A, Scultetus AH, Arnaud F, Dickson LJ, Chun S, McNamee G, Auker CR, McCarron RM, Mahon RT: The emulsified PFC oxycyte® improved oxygen content and lung injury score in a swine model of oleic acid lung injury (OALI). Lung 2016;194:945-957.

35 Zhou W, Fong MY, Min Y, Somlo G, Liu L, Palomares MR, Yu Y, Chow A, O’Connor ST, Chin AR, Yen Y, Wang Y, Marcusson EG, Chu P, Wu J, Wu X, Li AX, Li Z, Gao H, Ren X, Boldin MP, Lin PC, Wang SE: Cancer-secreted miR-105 destroys vascular endothelial barriers to promote metastasis. Cancer Cell 2014;25:501-515.

-36 Tornavaca O, Chia M, Dufton N, Almagro LO, Conway DE, Randi AM, Schwartz MA, Matter K, Balda MS: ZO-1 controls endothelial adherens junctions, cell-cell tension, angiogenesis, and barrier formation. J Cell Biol 2015;208:821-838.

-37 Qiu AW, Liu QH, Wang JL: Blocking IL-17a alleviates diabetic retinopathy in rodents. Cell Physiol Biochem 2017;41:960-972.

38 Watari A, Sakamoto Y, Hisaie K, Iwamoto K, Fueta M, Yagi K, Kondoh M: Rebeccamycin attenuates TNF- $\alpha$ induced intestinal epithelial barrier dysfunction by inhibiting myosin light chain kinase production. Cell Physiol Biochem 2017;41:1924-1934.

-39 Gabrys D, Greco O, Patel G, Prise KM, Tozer GM, Kanthou C: Radiation effects on the cytoskeleton of endothelial cells and endothelial monolayer permeability. Int J Radiat Oncol Biol Phys 2007;69:1553-1562.

40 Dudek SM, Camp SM, Chiang ET, Singleton PA, Usatyuk PV, Zhao Y, Natarajan V, Garcia JG: Pulmonary endothelial cell barrier enhancement by FTY720 does not require the S1P1 receptor. Cell Signal 2007;19:1754-1764.

-41 Dudek SM, Garcia JG: Cytoskeletal regulation of pulmonary vascular permeability. J Appl Physiol 2001;91:1487-1500.

42 van Hinsbergh VW, van Nieuw Amerongen GP: Intracellular signalling involved in modulating human endothelial barrier function. J Anat 2002;200:549-560.

43 Parker WH, Qu ZC, May JM: Intracellular ascorbate prevents endothelial barrier permeabilization by thrombin. J Biol Chem 2015;290:21486-21497. 